\title{
Avaliação dos níveis de ruído, luz e calor em máquinas de colheita florestal ${ }^{1}$
}

\author{
$\overline{\text { Luciano J. Minette }^{2} \text {, Emília P. da Silva }}{ }^{3}$, Amaury P. de Souza ${ }^{3}$ \& Kátia R. Silva ${ }^{4}$
}

\begin{abstract}
RESUMO
Esta pesquisa foi desenvolvida com dados coletados em áreas de colheita de madeira em três empresas do Estado de Minas Gerais; o objetivo geral foi avaliar os níveis de ruído, luz e calor, em máquinas de colheita florestal. Foram avaliados os postos de trabalho das seguintes máquinas: Feller-Buncher, Skidder, Garra-Traçadora, Traçador Mecânico e Carregador Florestal e os níveis de ruído medidos com o uso de um dosímetro, a iluminação através de um luxímetro digital e a exposição ao calor com o IBUTG. Na empresa 1, os dois tratores florestais avaliados enquanto parados emitem o mesmo nível de ruído, possuem luz interna e boas condições térmicas; na empresa 2, para as três máquinas avaliadas o nível de ruído está abaixo do limite recomendado pela NR 15, as cabines possuem luz interna e climatização regulável e na empresa 3 todas as máquinas apresentaram níveis de ruído superiores ao permitido pela legislação brasileira, o carregador florestal e o Mini-skidder apresentaram iluminação inadequada e os índices de temperatura efetiva estão fora da zona de conforto térmico para todas as máquinas. Conclui-se que todas as máquinas utilizadas pela empresa 3 estão em desconformidade ergonômica
\end{abstract}

Palavras chave: condições de trabalho, ergonomia, riscos ambientais

\section{Evaluation of noise, light and heat levels of forest harvesting machines}

\begin{abstract}
This research was developed with data collected in areas of wood harvesting by three companies of the State of Minas Gerais, Brazil. The general objective was to evaluate the level of noise, light and heat of forest harvesting machines. The work stations of the following machines were evaluated: Feller-Buncher, Skidder, Bucking Tongs, Mechanical Bucking and Forest Loader. The noise levels were measured with the use of a dosimeter, the light with a digital luximeter and the heat exposure with the IBUTG. At company 1, the two evaluated forest tractors, while stopped, presented the same level of noise, both had internal lighting and good thermal conditions. At company 2, for the three evaluated machines, the level of noise was below the limits recommended by the NR 15. The cabins had internal light and thermal regulation. At company 3, all the machines showed noise levels above those allowed by the Brazilian legislation. The forest loader and the mini-skidder showed poor lighting and the indexes of effective temperature were outside the thermal comfort zone for all machines. It is concluded that all the machines used by company 3 are ergonomically non-complient.
\end{abstract}

Key words: work conditions, ergonomy, environmental risks

\footnotetext{
1 Trabalho desenvolvido com apoio financeiro da FAPEMIG

2 Departamento de Engenharia Elétrica e de Produção/UFV, PH Rolfs s/n, CEP 36570-000, Viçosa, MG. Fone: (31) 3899-2721. E-mail: minetti@ufv.br

3 DEF/UFV. Fone: (31) 3899-3229. E-mail: amaurysouza@ufv.br.

${ }_{4}^{4}$ Pesquisadora do Grupo Orsa Florestal S.A. CEP 68240-000, Monte Dourado, PA. Fone: (93) 3736-6772. E-mail: krsilva@orsaflorestal.com.br
} 


\section{INTRODUÇÃO}

Com o aumento da área de florestas plantadas no Brasil, sobretudo depois do advento dos incentivos fiscais, notou-se a necessidade de buscar sistemas de colheita que proporcionassem um rendimento maior, menor custo e melhor aproveitamento, nos quais as operações fossem mais bem adaptadas ao trabalhador.

Em razão dessas necessidades, a mecanização das atividades de colheita passou a ser mais estudada, embora não tenha conseguido eliminar todos os problemas ocupacionais que acometem os trabalhadores florestais; outros riscos, como ruído, luminosidade e calor, continuaram a fazer parte do seu dia-a-dia.

Segundo Fiedler (1995) as máquinas são, na maioria das vezes, importadas ou adaptadas de outras máquinas e de custos elevados, o que exige o máximo aproveitamento de todas as suas funções menosprezando, muitas vezes, as condições de trabalho, principalmente o homem que opera esta máquina, forçando-o a adaptar-se às condições da máquina relegando, desta maneira, os princípios ergonômicos.

Os operadores de máquinas, quando expostos a níveis de ruídos elevados, podem ter perda auditiva que, no início, é apenas temporária, podendo gerar a PAIR (perda auditiva induzida pelo ruído), que é um dano permanente, além de perturbações do estado de alerta e sono (Kroemer \& Grandjean, 2005).

Quando o clima no posto de trabalho é desconfortável, ocorrem indisposição e fadiga, diminuindo a eficiência e aumentando os riscos de acidentes, em virtude do calor ou mesmo da insolação excessiva em uma jornada de trabalho (Grandjean, 1982). Sempre que possível os postos de trabalho devem conter termostato para ajuste do clima, sendo a temperatura ajustável ao esforço físico do trabalhador; devese evitar umidade ou secura exagerada, superfícies muito quentes ou frias e correntes de ar (Iida, 1990).

De acordo com Couto (1995), a iluminação adequada se constitui em um dos principais itens para o conforto humano, produtividade e qualidade de vida, razão por que se torna relevante que tanto o campo de trabalho quanto os mecanismos de acesso à máquina estejam devidamente iluminados.

O desconforto visual pode provocar sensação de cansaço nos olhos, dor, irritabilidade e vermelhidão obrigando, muitas vezes, o trabalhador a adotar posturas e movimentos inadequados buscando situações de conforto visual (Rio \& Pires, 2001).

Com o início de estudos enfocando a parte ergonômica dos sistemas de colheita mecanizados, começou-se a perceber que, para aumentar o rendimento da operação e diminuir o índice de doenças ocupacionais e acidentes, o posto de trabalho tinha que estar adaptado às características do trabalhador, proporcionando-lhe melhor visibilidade, com comandos ajustados à sua postura de trabalho e com maior conforto e segurança.

O objetivo com este trabalho foi avaliar os níveis de ruído, luz e calor em máquinas de colheita florestal no estado de Minas Gerais e, desta forma, fornecer informações que contribuam para a melhoria das condições de trabalho.

\section{MATERIAL E MÉTODOS}

\section{Local de estudo}

Este trabalho foi desenvolvido com dados levantados em áreas de colheita de madeira de eucalipto, em três empresas do Estado de Minas Gerais, nos meses de fevereiro e março de 2002, com as seguintes características climáticas (Golfari, 1975):

Empresa 1: a temperatura média anual varia de 19 a $22{ }^{\circ} \mathrm{C}$; a precipitação média anual de 1.150 a $1.450 \mathrm{~mm}$ e o tipo de clima é subtropical úmido a subúmido.

Empresa 2: a temperatura média anual varia de 19 a $22{ }^{\circ} \mathrm{C}$; a precipitação média anual varia de 1.150 a $1.450 \mathrm{~mm}$; seu regime de distribuição é periódico, predominando no semestre mais quente. O clima predominante é o subtropical úmido a sub-úmido.

Empresa 3: a temperatura média anual varia entre 20 e $23^{\circ} \mathrm{C}$; a precipitação média anual entre 1.300 e $1.800 \mathrm{~mm}$ e o clima é subtropical úmido.

\section{População e amostragem}

Foram avaliadas treze máquinas de colheita de madeira: um trator florestal derrubador-amontoador (feller-buncher) sobre esteira e cabeçote de disco e dois tratores florestais derrubadores-amontoadores (feller-buncher) sobre rodas, um com cabeçote de tesoura e outro com cabeçote de disco; três tratores florestais arrastadores (skidder); um trator agrícola arrastador-empilhador (mini-skidder); três traçadores mecânicos e três carregadores florestais.

\section{Níveis de ruído no posto de trabalho}

Os níveis de ruído foram medidos em todas as máquinas estudadas com o uso de um dosímetro da marca Bruel, instalado na altura do ouvido esquerdo do operador. Os resultados foram analisados com base nos limites de tolerância para ruídos contínuos ou intermitentes, estabelecidos pela Legislação Brasileira, consoantes a Norma Regulamentadora número 15 da Lei 6514, aprovada pela Portaria 3214, de oito de junho de 1978.

\section{Luminosidade no posto de trabalho}

A iluminação fornecida para o campo de trabalho foi medida com o uso de luxímetro digital com fotocélula, da marca Lutron LX - 101, de acordo com critérios padrões, da Norma Brasileira NBR 5413/92 da Associação Brasileira de Normas Técnicas (ABNT) e a análise, com base nos critérios de adequação apropriada à natureza da atividade e uniformidade de distribuição no campo de trabalho.

\section{Condições térmicas no posto de trabalho}

As variáveis do clima no posto de trabalho foram medidas através do termômetro digital de IBUTG (temperatura de bulbo seco e bulbo úmido, temperatura de globo e velocidade do vento), da marca Wibget, modelo RSS-241 e comparadas com os limites estabelecidos pela Legislação 
Brasileira de Ergonomia, Norma Regulamentadora 17, da Lei 6514, aprovado pela Portaria 3751, de 23 de novembro de 1990.

\section{RESULTADOS E DISCUSSÃO}

\section{Empresa 1}

\section{Níveis de ruído no posto de trabalho}

Na avaliação do feller-buncher, parado, com cabine fechada, ar condicionado ligado e com motor na máxima rotação, obteve-se um nível de ruído no ouvido esquerdo do operador de $80 \mathrm{dBA}$; e com o acionamento do disco de corte, o nível de ruído passou para $89 \mathrm{dBA}$.

Durante a realização do ciclo operacional de corte o nível de ruído equivalente (Leq) foi de $89 \mathrm{dBA}$, valor acima do permitido pela legislação brasileira, que é de $86 \mathrm{dBA}$ em uma jornada de sete horas de trabalho diário. O nível equivalente de ruído pode ser influenciado pela alta rotação e pelo contato dos dentes do disco com o tronco das árvores, na etapa de corte.

O nível de ruído emitido pelo Skidder, parado, com cabine fechada, ar condicionado ligado e com o motor na máxima rotação, foi de $80 \mathrm{dBA}$.

Durante o ciclo operacional de arraste o nível de ruído equivalente (Leq) foi de $83 \mathrm{dBA}$, menor que o valor permitido pela legislação brasileira, que é de $86 \mathrm{dBA}$ para uma jornada de sete horas de trabalho diário.

\section{Luminosidade no campo de trabalho}

Tanto o feller-buncher quanto o skidder possuem luz interna, porém a plataforma e os degraus não apresentam iluminação, podendo provocar quedas e acidentes, em cujas condições os trabalhadores florestais precisam ter percepção e atenção para exercer suas tarefas podendo, assim, minimizar os riscos ocupacionais.

Silva et al. (2003) também apresentou resultado semelhante e afirmou que, apesar do feller-buncher apresentar quatro faróis dianteiros, um traseiro e a cabine ter luz interna, a plataforma e os degraus não têm iluminação.

De acordo com Souza \& Minette (2002) na colheita florestal é comum encontrar locais de trabalho e máquinas incorretamente iluminados, que podem contribuir para o aumento da fadiga visual, erros e acidentes, além de uma influência psicológica negativa sobre os trabalhadores e, conseqüentemente, na produtividade das máquinas.

\section{Condições térmicas}

A borracha de vedação da porta do feller-buncher é fixada na estrutura da cabine; ao subir e descer da máquina, o operador pode pisá-la por se encontrar sobre a plataforma do piso, podendo danificá-la, contribuindo para um isolamento deficiente gerando, desta forma, desconforto térmico ao operador e até mesmo um isolamento deficiente do ruído produzido pela máquina.

A classificação da condição térmica dentro da cabine foi considerada boa pelos operadores das máquinas mas se o sistema de ar condicionado não estiver funcionando correta- mente, não é permitida a operação dos tratores devido ao grande desconforto térmico.

No trator skidder a borracha de vedação é fixada na porta, não podendo ser danificada pelos operadores quando do acesso ao posto de trabalho; este fato, aliado às várias saídas de ar, possibilitou classificar, segundo SKOGFORSK (1999) a condição térmica no posto do operador, em excelente.

\section{Empresa 2}

\section{Níveis de ruído no posto de trabalho}

Com o feller-buncher ligado em rotação normal, foi encontrada uma média no ouvido esquerdo do operador, na cabine, de 83,1 dBA; a mesma verificação foi feita com a máquina em operação tendo-se encontrado uma média de 84,2 dBA. Com o skidder ligado em rotação normal, deparou-se com uma média de 73,7 dBA, com a máquina em operação de 78,9 dBA. Para a garra-traçadora ligada em rotação normal, tem-se uma média de 74,2 dBA no ouvido esquerdo do operador e, com a máquina em operação de 74,9 dBA, pôde-se constatar que o nível de ruído para as três máquinas avaliadas está abaixo do limite aceitável no Brasil, para uma jornada de $8 \mathrm{~h}$ de trabalho, que é de $85 \mathrm{dBA}$.

De acordo com Saliba (2001), o limite de tolerância para ruído contínuo/intermitente é 85 dBA para a exposição diária de 8 h. Diferente, as diretrizes ergonômicas para máquinas florestais consideram ergonomicamente ótimo um valor menor que $65 \mathrm{dBA}$, para a máquina ligada e menor que 80 dBA, para a máquina em operação (Skogforsk, 1999).

\section{Luminosidade no campo de trabalho}

O feller-buncher possui cabine com luz interna; no entanto, a plataforma e os degraus não têm iluminação; essas mesmas condições podem ser observadas no skidder e na garra-traçadora; pode-se dizer que as condições de iluminação não são ideais para as máquinas, estando em desacordo com as diretrizes ergonômicas.

Segundo Souza \& Minette (2002), na colheita florestal o nível de iluminação adequada para as diferentes atividades deve enquadrar-se na faixa de 100 a 300 lux; essas máquinas apresentam nível de iluminação abaixo do indicado; por outro lado, esses resultados diferem dos estudos de Fiedler (1995), que evidenciou boas e médias condições de iluminamento do local de trabalho para o feller-buncher e o skidder, respectivamente.

\section{Condições térmicas}

Todas as máquinas avaliadas apresentam climatização regulável, ar com três velocidades, termostato e a mudança de ar responde rapidamente; as cabines são equipadas com sistema automático de controle de clima e com controles individualmente ajustáveis de fácil operação, resultados que corroboram com os estudos de Silva et al. (2003), em que o feller-buncher apresenta todas as características citadas.

Os valores climáticos recomendados para o posto do operador, quando o trabalho é realizado pelas mãos e com o operador sentado, permitem a variação da temperatura do ar entre 19 a $22{ }^{\circ} \mathrm{C}$, com umidade relativa entre 40 a $70 \%$ e velocidade do ar de $0,10 \mathrm{~m} \mathrm{~s}^{-1}$. Quando a operação exige que 
o operador trabalhe em pé, a temperatura deve estar de 2 a $4{ }^{\circ} \mathrm{C}$ menor e a velocidade do ar acima de $0,10 \mathrm{~m} \mathrm{~s}^{-1}$, em relação à realização da operação sentada (Delgado, 1991).

\section{Empresa 3}

\section{Níveis de ruído no posto de trabalho}

Todas as máquinas estão com níveis de ruído acima dos limites máximos permitidos pela legislação brasileira para uma jornada de $8 \mathrm{~h}$, que é de $85 \mathrm{dBA}$, haja vista que as melhores situações são encontradas no carregador florestal MJ 10070 (86 dBA), traçador mecânico Caterpillar E 200 B (88 dBA) e traçador Poclain (90 dBA).

Segundo Seixas et al. (2004), o skidder apresenta os piores níveis de ruído, o feller-buncher e o traçador mecânico indicam resultados acima do limite de $85 \mathrm{dBA}$, atingindo 106 e $101 \mathrm{dBA}$, respectivamente, o mesmo autor afirma ainda que já existem novos modelos de máquinas florestais que não prejudicam a capacidade auditiva do trabalhador, devendose observar o uso de modelos antigos em que o ruído é mais elevado; caso não haja possibilidade de inovação tecnológica imediata, recomenda-se o uso de protetores auriculares.

\section{Luminosidade no campo de trabalho}

A análise do carregador florestal MJ 10070 foi considerada boa e o feller-buncher, os traçadores mecânicos, o carregador florestal Motocana e o skidder, foram avaliados como médios, enquanto o mini-skidder e o carregador florestal MJ 3047 o foram como ruins pois, segundo a opinião dos operadores, dificultam o trabalho noturno.

No caso do trabalho em máquinas florestais, um nível de iluminação de 200 a 300 lux é recomendado. Deve-se levar em conta, também, o contraste entre o local focalizado, suas imediações e a presença de brilho no campo visual. No controle da iluminação é oportuno ressaltar a necessidade de evitar a distração visual, a fadiga e o desconforto da visão (Iida \& Wierzzbicki, 1978).

\section{Condições térmicas}

Os resultados do teste $\mathrm{t}$ indicaram que não existem diferenças significativas $(P<0,05)$ de temperaturas efetivas nas distintas partes do corpo nem destas com as temperaturas efetivas externas no feller-buncher, skidder, nos traçadores mecânicos Poclain e Caterpillar E 200 B, trabalhando com cabinas abertas e carregadores florestais MJ 10070, MJ 3047 e Motocana.

Verificou-se, através dos resultados dos testes que o miniskidder é uma máquina que apresenta variação brusca de temperatura efetiva em partes distintas do corpo.

Nos traçadores mecânicos Poclain e Caterpillar E 200 B, trabalhando na condição que deveria ser normal (cabina fechada), há variação brusca de temperatura efetiva em relação à temperatura efetiva externa, o que leva à necessidade de climatização interna das cabinas.

Na época do estudo os postos de trabalho apresentaram em todas as máquinas, índices de temperatura efetiva fora da zona de conforto térmico ressaltando-se que todas elas tinham temperaturas efetivas internas mais elevadas que as externas.

\section{CONCLUSÕES}

1. As máquinas (carregador florestal, feller-buncher, traçador mecânico, skidder e mini-skidder) utilizadas pela empresa 3 na colheita florestal, apresentaram níveis de ruído superiores ao permitido pela legislação brasileira, sendo que em todos os postos de trabalho os índices de temperatura efetiva estão fora da zona de conforto térmico.

2. Das máquinas avaliadas, o feller-buncher, skidder, guarra-traçadora, carregador florestal e o mini-skidder, possuem condições ruins de iluminamento, sem iluminação adequada da plataforma e dos degraus de acesso, podendo provocar quedas e acidentes.

\section{LITERATURA CITADA}

Couto, H. A. Ergonomia aplicada ao trabalho: O manual técnico da máquina humana. Belo Horizonte: Ergo, 1995. 353p.

Delgado, L. M. El tractor agrícola características y utilizacion. Madrid: Laboreo Solotractor, 1991. 235p.

Fiedler, N.C. Avaliação ergonômica de máquinas utilizadas na colheita de madeira. Viçosa: UFV, 1995. 126p. Dissertação Mestrado

Golfari, L. Zoneamento ecológico do Estado de Minas Gerais. Belo Horizonte: PRODEPEF/PNUD/FAO/IBDF. 1975. 65p. Série Técnica, 3

Grandjean, E. Fitting the task to the man - an ergonomic approach. London: Taylor \& Francis, 1982. 379p.

Kroemer, K. H. E; Grandjean E. Manual de ergonomia: Adaptando o trabalho ao homem. 5.ed. Porto Alegre: Bookman, 2005, 327p.

Iida, I. Ergonomia: Projeto e produção. São Paulo: Edgard Blucher, 1990. 465p.

Iida, I.; Wierzzbicki, H. A. J. Ergonomia. Notas de aula. São Paulo: EPUSP, 1978. 282p.

Rio, R. P.; Pires, L. Ergonomia: fundamentos da prática ergonômica. 3.ed. Belo Horizonte: Health, 2001, 225p.

Saliba, T. M. Manual prático de avaliação e controle de ruído: PPRA. 2.ed. São Paulo: LTr, 2001.118p.

Seixas, F.; Barbosa, R. A.; Rummer, R. Tecnologia protege saúde do operador. Revista Madeira, v.82, p.68-73, 2004.

Silva, C. B.; Sant’Anna, C. M.; Minette, L. J. Avaliação ergonômica do "feller-buncher" utilizado na colheita de eucalipto. Revista Cerne, v.9, n.1, p.109-118, 2003.

SKOGFORSK. The Forest Research Institute of Sweden. Ergonomic guidelines for forest machines. Uppsala: Swedish National Institure for Working Life, 1999. 86p.

Souza, A. P.; Minette, L. J. Ergonomia aplicada ao trabalho In. Machado, C. C. Colheita florestal. Viçosa: UFV, 2002. 468p. 